\title{
Characterization of simulation centers and programs in Latin America according to the ASPIRE and SSH quality criteria
}

Soledad Armijo-Rivera ${ }^{1 *}$ (D), Felipe Machuca-Contreras ${ }^{2} \mathbb{D}$, Norma Raul ${ }^{3} \mathbb{D}$, Saionara Nunes de Oliveira ${ }^{4} \mathbb{D}$, Ismael Ballesteros Mendoza ${ }^{5}$, Héctor Shibao Miyasato ${ }^{6}$ (i) and Diego Andrés Díaz-Guio ${ }^{7}$ (I)

\begin{abstract}
Background: Latin American clinical simulation has had an important development; there are no studies that characterize simulation centers and programs in the entire region. The aims of this work are to characterize the current state of simulation-based education in the health sciences, to determine the structure of Latin American simulation centers in terms of teaching, research, and continuing medical education (CME), as well as to determine the perception of quality based on international standards of simulation practices for the directors of Latin American centers.

Methods: A quantitative, descriptive, cross-sectional study with a demographic questionnaire and a Likert-type survey was conducted to the directors of the simulation centers found in Latin America.

Results: Four hundred eight simulation centers were documented, the survey was answered by 240 directors, and the data from 149 were complete responses on the 42 quality self-perception scale and considered valid on further analyses related to the quality of the programs. Most of the centers that responded correspond to Chile, Brazil, and Mexico (37.5\%, 18.1\%, 12.7\%). 84\% of the centers are university-based, and $71 \%$ of the centers are medium-sized, with less than 10 instructors (54\%). The directors are mostly women (61.7\%), medical doctors (50\%), and nurses (40\%), with clinical specialization (37\%), master's degree (53\%), and doctorate (13\%). 75\% have completed a simulation instructor course, and $6 \%$ have developed a fellowship. Most consider the maintenance of international quality standards to be relevant in their centers, mainly in reflective training techniques, ethical aspects, and adequate learning environments.

Conclusions: Simulation-based education in health sciences has had an increasing development in Latin America, within a university environment, in an important academic specialization process that seeks to adhere to highquality standards to improve training and development of clinical skills, human factors, and critical thinking. We recommend starting accreditation processes in Latin America and studies that measure the quality of simulationbased education in our region, based on objective observations more than in self-reporting.
\end{abstract}

Keywords: Simulation training, High fidelity simulation training, Quality assurance, Health care education, Medical simulation centers

\footnotetext{
* Correspondence: soledad.armijo@gmail.com

${ }^{1}$ Núcleo de Simulación Interdisciplinar, Facultad de Medicina Clínica Alemana de Santiago Universidad del Desarrollo, Avenida Las Condes 12438 Lo Barnechea, Santiago, Chile

Full list of author information is available at the end of the article
}

C The Author(s). 2021 Open Access This article is licensed under a Creative Commons Attribution 4.0 International License, which permits use, sharing, adaptation, distribution and reproduction in any medium or format, as long as you give appropriate credit to the original author(s) and the source, provide a link to the Creative Commons licence, and indicate if changes were made. The images or other third party material in this article are included in the article's Creative Commons licence, unless indicated otherwise in a credit line to the material. If material is not included in the article's Creative Commons licence and your intended use is not permitted by statutory regulation or exceeds the permitted use, you will need to obtain permission directly from the copyright holder. To view a copy of this licence, visit http://creativecommons.org/licenses/by/4.0/. The Creative Commons Public Domain Dedication waiver (http://creativecommons.org/publicdomain/zero/1.0/) applies to the data made available in this article, unless otherwise stated in a credit line to the data. 


\section{Background}

Latin America is a region of the American continent whose languages, derived from Latin, are mainly Spanish and Portuguese. This territory is made up of approximately 20 nations and has an extension of 22,000,000 $\mathrm{km}^{2}$, where about 626 million people live, with ethnic, cultural [1], economic, and public education financing diversity [2].

Latin America is different from regions in which clinical simulation training and research criteria or recommendations are available for simulation-based education such as Europe, the UK, the USA, and Canada [3-5].

Simulation has been reported in Latin America as a teaching tool in prelicensure [6, 7], postgraduate [8], and cardiopulmonary resuscitation programs [9], and as an assessment tool inside OSCEs (Objective and Structured Clinical Examination) [10-12]. Information regarding simulation centers in Latin America is scarce [13, 14]. There are no studies that characterize simulation centers and their programs or quality.

The quality of clinical simulation occupies an important part of the agenda of scientific societies in Europe and North America, focusing both on the standards and recommendations of good practice [15], as well as on the accreditation criteria to measure quality. The accreditation criteria for the simulation centers of the Society for Simulation in Healthcare (SSH), which consider elements of systems integration [3], the criteria of the Association for Medical Education in Europe (AMEE) for accreditation of programs [4], the standards for simulation training developed by the International Nursing Association for Clinical Simulation and Learning (INACSL) [5], and the Association of Standardized Patient Educators (ASPE) [16] are examples of standards of quality that do not exists for Latin America.

Currently, in Latin America, there is the need to work on standardized aspects of the quality of simulationbased education; nonetheless, until now, there is no consensus instrument to measure the quality of our centers and programs.

The aims of this work are to characterize the current state of simulation-based education in the health sciences, to determine the structure of Latin American simulation centers in terms of teaching, research, and continuing medical education (CME), as well as to determine the perception of quality based on international standards of simulation practices for the directors of Latin American centers.

\section{Methods} Study design

A quantitative, descriptive, cross-sectional study using an online self-report instrument was conducted.

\section{Setting and participants}

For this study, we considered a simulation center or simulation program as an organization with dedicated resources, and a mission targeted to the use of simulation for education, assessment or research, that uses a substantial component of simulation as a technique [3].

Directors of simulation centers were asked to respond representing simulation centers in Latin American Spanish- and Portuguese-speaking countries.

An intentional sample was selected based on the defined population. A database was created with the contact emails that appeared on the institutional websites and was complemented by a snowball sampling technique to cover the greatest extent of the universe in the cases where a contact email was not available at the institutional website. To include centers that do not have a website, we used the information available from congress contacts. Once the database was constructed with the information known to the authors, we expanded it, identifying simulation center directors in each country from whom we requested contact information for centers not yet included in the database. No databases of country societies or the Latin American federation were used.

We also used data available on population, and the percentage of global Gross Domestic Product (GDP) spended on education and health in Latin American countries, obtained from public information on the CEPAL website for 2018 [17].

\section{Instrument development}

A group of researchers (two nurses and five medical doctors) trained in simulation, with experience in administering simulation centers and research, belonging to the Federación Latinoamericana de Simulación Clínica (FLASIC, www.flasic.org), constituted a committee to design the research protocol to develop the instruments.

Based on a literature review that included the accreditation criteria of SSH and ASPIRE, surveys used to characterize worldwide simulation centers [18-20], centers in European [21, 22] and Latin American single countries [14], and some definitions to report simulation centers resources and activities [23]. A two-part bilingual instrument (Spanish and Portuguese) was designed [24].

The selection of the SSH criteria was based on the fact that they include systems integration criteria that we needed to characterize the simulation centers of clinical institutions, and the ASPIRE criteria because they are based on elements of Medical Education. In addition, both SSH and ASPIRE have center and program accreditation processes. The survey includes the main criteria of both SSH and ASPIRE.

The first part is a characterization questionnaire with 19 questions, focusing on center information (country, type of institutions, infrastructure, metrics of activities, human 
resources and directors profile, simulation resources) and program orientations. In relation to the size of the centers, they were classified into groups according to the square meters reported (small $<122 \mathrm{~m}^{2}$, medium $122-1500 \mathrm{~m}^{2}$, large $1500-2900 \mathrm{~m}^{2}$, very large $>2900 \mathrm{~m}^{2}$ ). For the metrics of activities used in the questionnaire (number of participants per year, hours per participant, number of activities, and number of hours of room use), an explanation of how to calculate them was included [23].

The second part was developed through a modified eDelphi method based on the opinions of six Latin American experts to assess the self-perception of quality. The expert profile was a professional with more than 7 years of experience and postgraduate training in educational sciences and clinical simulation who had experience in administering simulation centers and training instructors.

A first draft of the second part of the instrument was created in Spanish with six dimensions and 42 items based on the accreditation criteria for SSH [3] and ASPIRE [4] simulation centers. This version passed through a three-step iterative creation process (e-Delphi) until it reached a complete consensus. The semantics, wording, and spelling were adjusted at the first Delphi step. The following stages did not generate changes in the instrument. As a result of that process, a preliminary Spanish version of this questionnaire was obtained [24]. The revised questionnaire maintained the initial number of dimensions and items.

The instrument was translated to Portuguese by a researcher, native in Portuguese and proficient in Spanish. A backward independent translation was performed from Portuguese to Spanish to corroborate the first. Finally, in terms of the semantics and cultural equivalence for the study, the Portuguese version was reviewed by two simulation instructors with Portuguese as their native language [26, 27].

The bilingual final instrument was composed of a demographic questionnaire with 19 items and a 42 items quality self-perception questionnaire Likert-type $(1=$ totally disagree to $5=$ totally agree).

The average lickert per item and dimension was calculated. A score was also calculated for each dimension and for the total scale, adding the score for each item.

\section{Data collection}

This study was carried out between January and May 2019. The survey was hosted on the Survey Monkey ${ }^{\circ}$ platform (https://es.surveymonkey.com/) and sent by email to the directors of the simulation centers in Latin America, with monthly reminders (four email reminders). There were no incentives for participation or completion of the survey.

\section{Statistical analysis}

The use of descriptive statistics for the characterization of the sample was considered. Cronbach's alpha was calculated as a measure of internal consistency of the selfperception of the quality questionnaire (alpha value> $0.70)[25,28]$. In the 42 items self-perception questionnaire of the instrument, good internal consistency with Cronbach's alpha of 0.95 was found.

The statistical package IBM Corp. Released 2015. IBM SPSS Statistics for Windows, Version 23.0. Armonk, NY: IBM Corp was used. The correlation analysis with demographic and economic data was performed with Microsoft Excell (version 16.52).

\section{Ethical approval}

Participants informed consent were obtained. The ethical committee approved the Research design in the Universidad del Desarrollo de Chile (CEI 46/2018) and the Federal University of Santa Catarina of Brazil (Parecer do Comitê de Ética N ${ }^{\circ}$ 3.206.561).

\section{Results}

\section{Characteristics of Latin American simulation centers}

Four hundred eight directors of simulation centers in Latin America were contacted. The distribution of those centers goes between 1 and 136 per country.

Using CEPAL information about countries' population, education GDP, and health GDP, we graphed the relationship with the number of simulation centers. There is a positive linear correlation between the number of centers v/s population (correlation coefficient 0,922 ) (Fig. 1)

149 directors sent complete responses (36.5\%) on the 42 quality self-perception scale and considered valid on further analyses related to the quality of the programs. Valid responses were obtained from 14 countries. The countries with the highest response rate were Chile (37.5\%), Brazil (18.1\%), and Mexico (12.7\%) (Fig. 2).

Most simulation centers were university linked (84\%), and only 12 centers linked to health institutions were reported, of which $50 \%$ were located in Chile.

Centers responding to the survey were in existence for an average of 7 years with a standard deviation of 6833 years and range from 0 to 58 years. The first simulation center in Latin America was created in 1961 in Peru and is still open to date. It is a surgical simulation center that reports that the resources are mainly biological models and surgical trainers. New simulation centers were created every year from 1998 to 2019 (Fig. 3). Between 2008 and 2016, about ten centers per year were created, and in the years 2017 and 2018, we observed the creation of about 20 centers per year. During the first half of 2019, 8 new simulation centers were created in the region. 


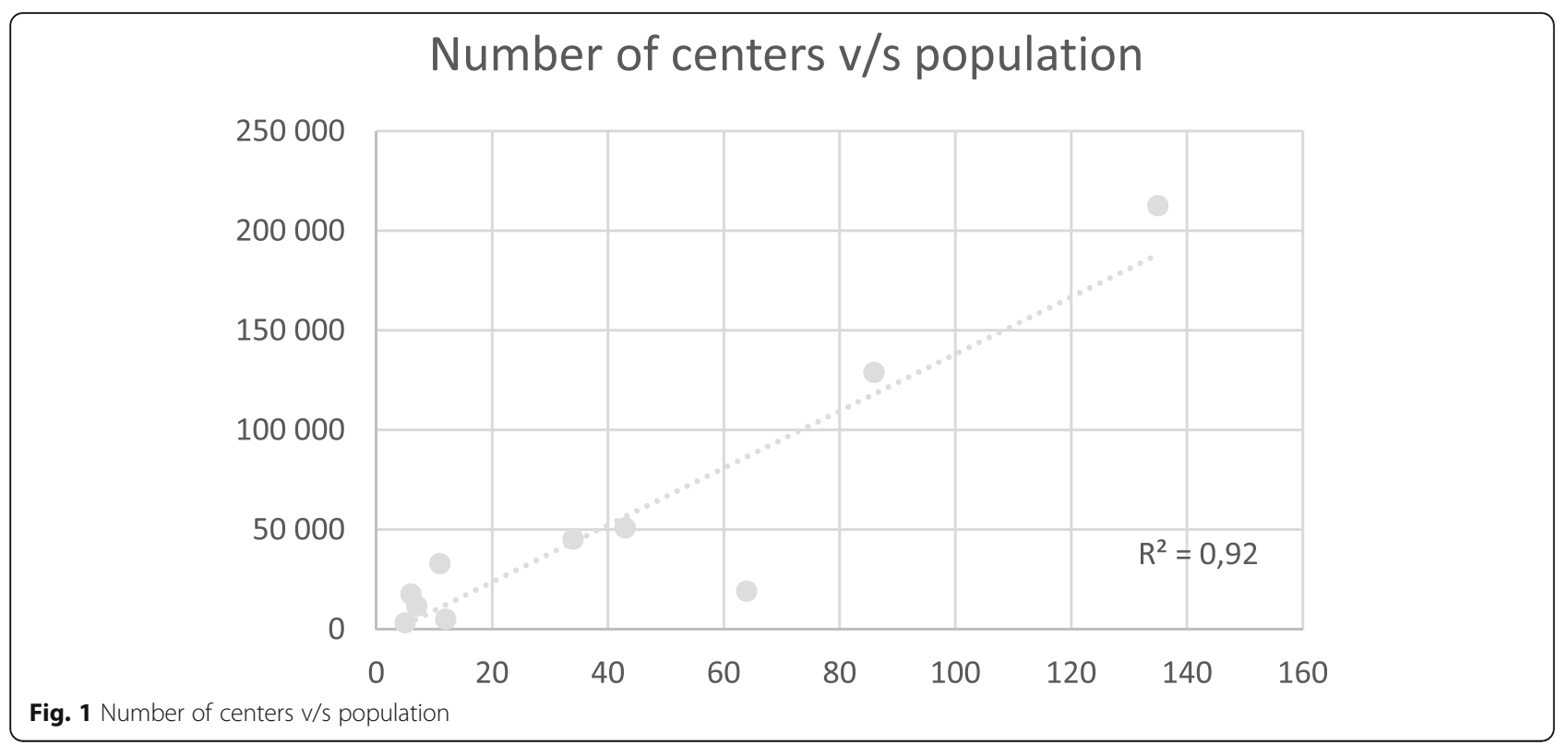

\section{Infrastructure and metric of activities}

The data reported in the logistics aspects are heterogeneous; the centers' area is declared between 8 and $4307 \mathrm{~m}^{2}$. The information was organized into quartiles, and the centers were categorized into small $<122 \mathrm{~m}^{2}$, medium $122-1500 \mathrm{~m}^{2}$, large $1500-$ $2900 \mathrm{~m}^{2}$, and very large $2900 \mathrm{~m}_{2}$. Twenty-five percent of simulation centers are small, and $71 \%$ are medium size. Heterogeneity was found in the number of participants per year, hours per participant, number of activities, and number of hours of room use (Table 1).

\section{Human resources and directors' profile}

Most simulation centers (54\%) have less than ten instructors and $8 \%$ more than 50 . Regarding the profile of the simulation center directors, $61.7 \%$ are women, $50 \%$ are medical doctors (MD), 40\% nurses, and 5\% engineers. Thirty-seven percent have a clinical specialty, $53 \%$ have a master's degree, and $13 \%$ have doctoral training. In the specific training in simulation, $75 \%$ have completed an instructor course, $6 \%$ have completed a fellowship in simulation, 5.4\% report having Certified Healthcare Simulation Educator (CHSE), and 17\% report not having specific training in simulation-based education.

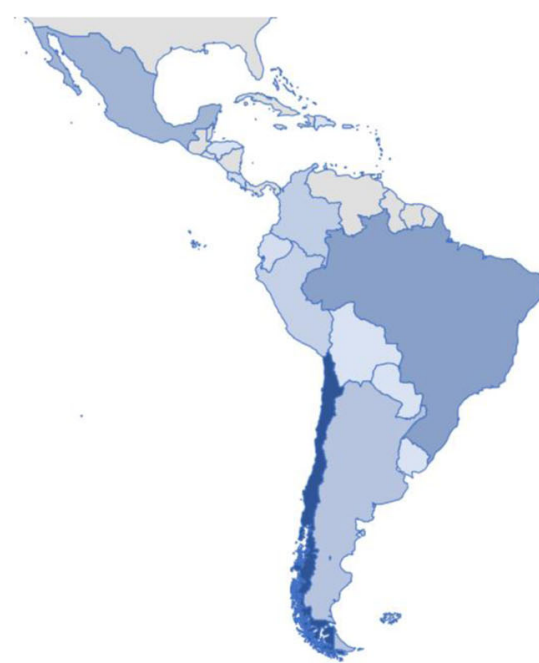

\begin{tabular}{|l|c|c|}
\hline Country & $\begin{array}{c}\text { Number of centers } \\
\text { contacted }\end{array}$ & $\begin{array}{c}\text { Numbers of complete } \\
\text { responses }\end{array}$ \\
\hline Argentina & 34 & 13 \\
\hline Brasil & 135 & 27 \\
\hline Bolivia & 7 & 1 \\
\hline Chile & 64 & 56 \\
\hline Colombia & 43 & 9 \\
\hline Costa Rica & 12 & 4 \\
\hline Ecuador & 6 & 3 \\
\hline Honduras & 1 & 1 \\
\hline México & 86 & 19 \\
\hline Paraguay & 2 & 1 \\
\hline Perú & 11 & 8 \\
\hline Puerto Rico & 5 & 5 \\
\hline República & & \\
\hline Dominicana & 1 & 1 \\
\hline Uruguay & 1 & 149 \\
\hline
\end{tabular}

Fig. 2 Number of centers contacted by country and complete responses to quality self-perception survey 


\section{Year of creation of new simulation centers in latinamerica}

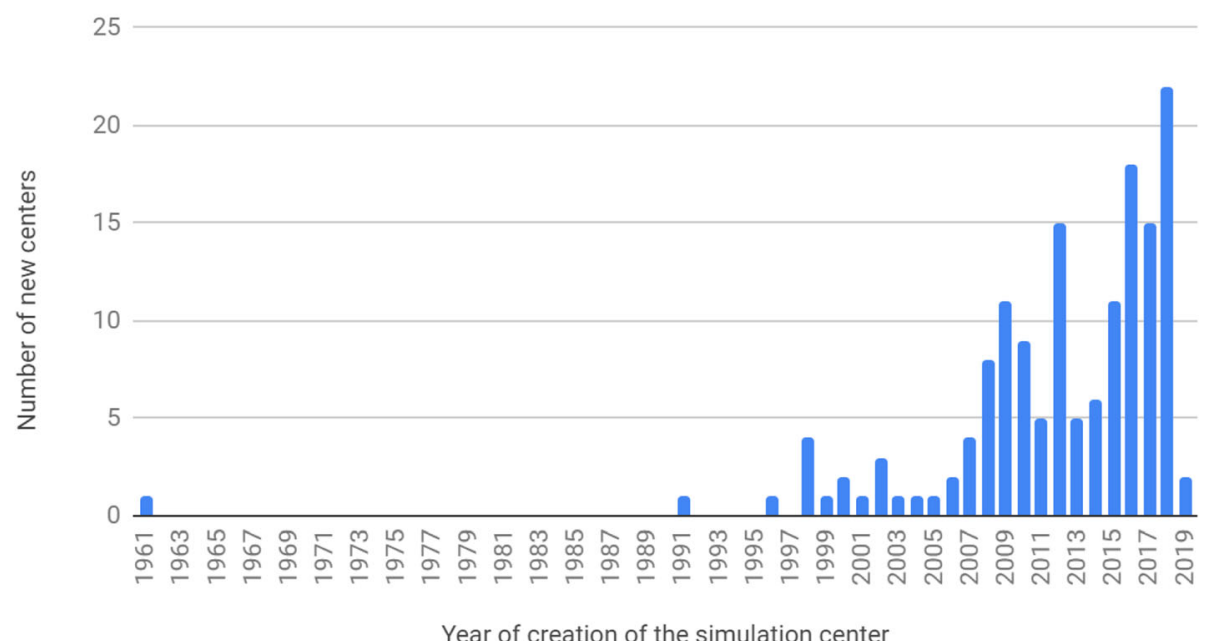

Fig. 3 Year of creation of new simulation centers in latinamerica

\section{Simulation resources and programs' orientation}

Regarding the types of simulation resources used in simulation centers, the most commonly used are highcost simulators (81\%) and simulators for procedures (79\%). The third place among the simulation resources used in the centers corresponds to simulated patients. The least used resources correspond to biological samples and animal models, which are used in centers dedicated to surgical training (Table 2).

Regarding the intention of acquiring new simulators for next year, $65 \%$ of respondents do not want to.

When asked about program orientations, most centers report that their programs intend to improve the practice and development of clinical skills (94\%), critical thinking (93\%), and human factors (84\%) (Table 2).

\section{Self-perception of quality}

The research dimension was the one with the lowest Likert average $(m=3.3)$, and the $\mathrm{SSH}$ teaching/learning dimension the one with the highest Likert $(m=4.1)$ global score by dimensions (Table 3 ).

The individual descriptors in which the Likert average was higher were, in decreasing order, those related to adequate learning environments (item 29, SSH Teaching/Learning Criteria, $m=4.4$ ) ethical aspects (item 20, SSH CORE Criteria, $m=4.4$ ) and reflective training techniques (item 7 , ASPIRE Criteria, $m=4.3$ ) as seen in Table 3.

The lowest average Likert in individual descriptors was 3.0 in item 12, corresponding to ASPIRE Criteria: "The faculty of the institution (or its students) conducts

Table 1 Characteristics of Latin American simulation centers

\begin{tabular}{|c|c|c|c|c|c|}
\hline Characteristics & $\begin{array}{l}\text { Number of } \\
\text { valid } \\
\text { responses }\end{array}$ & Minimum & Maximum & Average & $\begin{array}{l}\text { Std. } \\
\text { deviation }\end{array}$ \\
\hline Center square meters & 143 & 8 & 4307 & 425.9 & 598.5 \\
\hline $\begin{array}{l}\text { Number of participants (count the people who participate in each sesion and if } \\
\text { someone participates in more than one can count it twice or more. Calculate based } \\
\text { on the last full year) }\end{array}$ & 96 & 6 & 60000 & 3116.7 & 8171.1 \\
\hline $\begin{array}{l}\text { Number of hours per participant }(1 \mathrm{~h} \text { per participant }=1 \mathrm{~h} \text { class } \times 1 \text { participant. If a } \\
\text { class lasts } 4 \mathrm{~h} \text { and had } 10 \text { participants, that is } 40 \mathrm{~h} \text { per participant. Calculate based } \\
\text { on the last full year) }\end{array}$ & 69 & 2 & 3672227 & $59,711.4$ & $441,908.7$ \\
\hline $\begin{array}{l}\text { Number of activities (each activity refers to the same block of hours during a day, } \\
\text { where a group of participants performed the same activity. Calculate based on the } \\
\text { last full year) }\end{array}$ & 73 & 2 & 4300 & 413.6 & 898.2 \\
\hline $\begin{array}{l}\text { Number of hours of room use (multiply the number of rooms by the class time. If } \\
\text { there are four rooms used for } 4 \mathrm{~h} \text { of class time, calculate } 16 \mathrm{~h} \text { of room use. } \\
\text { Calculate based on the last full year) }\end{array}$ & 71 & 2 & 74574 & 2912.9 & 9364.3 \\
\hline Director's age & 149 & 23 & 75 & 43.3 & 13.1 \\
\hline Number of programmatic orientations & 149 & 1 & 8 & 4.7 & 1.7 \\
\hline
\end{tabular}


Table 2 Distribution of centers who use simulation resources and declare orientation of simulation programs $(n=149)$

\begin{tabular}{|c|c|c|}
\hline Type of simulation resource used & $\begin{array}{l}\text { Number of centers who use that resource } \\
(n)\end{array}$ & $\begin{array}{l}\text { Percentage of center who use that resource } \\
\text { (\%) }\end{array}$ \\
\hline High-tech simulators & 120 & 81.1 \\
\hline Task trainers & 117 & 79.1 \\
\hline Simulated patients & 87 & 58.8 \\
\hline Standardized patients & 84 & 56.8 \\
\hline Moulage & 75 & 50.7 \\
\hline Handmade simulators & 46 & 31.1 \\
\hline Virtual simulators & 46 & 31.1 \\
\hline Bench surgical simulators & 33 & 22.3 \\
\hline Biological samples for surgery & 27 & 18.2 \\
\hline Animals for surgery & 10 & 6.8 \\
\hline Orientations of the simulation programs & $\begin{array}{l}\text { Number of centers who declare orientations } \\
\text { of the simulation programs }(n)\end{array}$ & $\begin{array}{l}\text { Percentage of centers who declare } \\
\text { orientations of the simulation programs (\%) }\end{array}$ \\
\hline $\begin{array}{l}\text { Teaching and evaluating clinical and } \\
\text { procedural skills }\end{array}$ & 140 & 94.6 \\
\hline $\begin{array}{l}\text { Promote critical thinking and problem-solving } \\
\text { skills }\end{array}$ & 138 & 93.2 \\
\hline Promote communication and teamwork & 125 & 84.5 \\
\hline Develop patient safety & 110 & 74.3 \\
\hline $\begin{array}{l}\text { Introduce and promote interprofessional } \\
\text { learning and practice }\end{array}$ & 84 & 56.8 \\
\hline Develop care that considers cultural variables & 41 & 27.7 \\
\hline Explore and analyze health systems practices & 41 & 27.7 \\
\hline $\begin{array}{l}\text { Specific training to present or take entrance } \\
\text { exams to medical-surgical residency }\end{array}$ & 24 & 16.2 \\
\hline
\end{tabular}

research related to simulation-based education," and in item 38, corresponding to SSH Research Criteria: "There is a designated individual who is responsible for administering research programs" (Table 3).

The higher score by dimension was obtained using ASPIRE criteria, and the lowest in SSH Research dimension (Table 4).

\section{Discussion}

Few studies show the specific characteristics of the simulation centers $[18,19]$, but they do not consider the orientations of the programs carried out in them. Our work is the first on a large scale in Latin America, and we found an acceptable response rate compared to works in a single country in the region [14].

In the recent Italian survey of simulated pediatric training, nearly $15 \%$ of the surveyees answered [21]; In Switzerland, Stocker obtained a response in $96 \%$ of hospital centers where they offered training in pediatrics; of these, $66.6 \%$ used clinical simulation in their teaching practice [22]. Sixty-six percent of residents surveyed, and $100 \%$ of program managers responded to the Canadian emergency medicine training survey [20].
Our response rate is lower than that reported in other latitudes and contexts. It may be given by the cultural diversity in Latin America, by the differences in the development of the simulation in the different countries of the region, or because this is the first time that is carried out surveys of this type.

The number of simulation centers in Latinamerican Countries shows large differences. Since these are countries with different economic and population sizes, it is convenient to compare not only in absolute terms, but also in relation to the level of wealth and number of inhabitants of the countries. We found a positive linear correlation between the number of centers v/s population, with a country that deviates from the tendency, with a higher proportion of centers for the number of inhabitants. Moreover, it is precisely this country that reports the most simulation centers associated with clinical institutions, an area in which it is possible that the rest of Latin America will expand simulation centers in the future given the worldwide trends on systems integration of clinical simulation [20-22]. We do not believe we can recommend a standard of centers per number of inhabitants at the present time or estimate how much this growth will reach a plateau. 
Table 3 Mean average of Likert points by every item of quality self-perception instrument (ASPIRE and SSH criteria) $(n=149)$

Items Likert

\section{Aspire-based criteria}

1. Your simulation center has clear objectives aligned with the priorities and objectives of your institution and/or manages to influence the culture of your organization.

2. Your simulation center has a policy or definitions to guarantee that the development of its programs is carried out using a systematic approach to curriculum design, considering learning theories that support its programs.

3. Your simulation center has a policy or definitions to evaluate the implemented programs and thus promote continuous improvement in its practices.

4. At your simulation center, a systematic process is used to align simulation technologies and methodologies with your defined training needs.

5. In your simulation center, the development of educational programs is carried out using the evidence of simulation effectiveness for teaching and training as a guide.

6. In your simulation center, a rigorous and standardized process is used to develop and implement validated performance evaluation instruments (considering their use for training and summative purposes).

7. Your simulation center incorporates evidence-based feedback and debriefing methods for training purposes.

3.8 simulation programs.

9. Your simulation center expects its teaching, administrative and technical staff to have experience in simulation-based education and supports its development by providing the resources necessary to achieve its objectives and maintain its activities.

10. The institution's simulation program has faculty experienced in conducting simulation-based educational research and supports its development by providing the resources necessary to achieve its objectives and maintain its activity.

11. At your center, innovation in simulation-based education is promoted.

12. The faculty of the institution (or its students) conducts research related to simulation-based education.

13. The centre's teachers promote simulation-based education nationally and internationally.

\section{Core criteria SSH}

14. There is a clear and publicly stated mission that specifically addresses the intent and functions of the simulation program, and how the program is linked to the larger organization, if it exists.

15. There is an organizational framework that provides adequate resources (fiscal, human and material) to support the mission of the program.

16. There is a strategic plan designed to accomplish the mission of the program.

17. There are written policies and procedures to ensure that the program provides high quality services, and that it meets its obligations and commitments.

18. The program has a process to determine which simulation modalities and relevant technologies are selected for use in various education, evaluation, research and / or systems improvement activities.

19. The program has a method of evaluating its general areas of programs and services, as well as educational, evaluation, and / or research activities so that they provide feedback for continuous improvement.

20. All activities, communications and relationships demonstrate a commitment to the highest ethical standards.

21. Adequate documentation and organizational policies and mechanisms are in place to ensure that data / evidence security and student confidentiality are maintained.

22. The program demonstrates a commitment to advocating for health simulation and contributes to the field of simulation.

23. The program offers comprehensive learning activities using simulation.

24. The program provides expert guidance for simulation education for instructors / educators and students.

25. Educational methods are reliable, valid, attractive and, when possible, based on evidence.

26. Appropriate simulation modalities are used to support learning objectives and design.

27. There is access to qualified educators for the educational activities provided. *

28. Curriculum design follows a rational process based on the theory of education currently understood.

4.0

29. Simulation activities are carried out in a suitable environment to optimize the achievement of learning objectives.

31. The program has a demonstrated ability to offer continuing education credits. 
Table 3 Mean average of Likert points by every item of quality self-perception instrument (ASPIRE and SSH criteria) ( $n=149)$ (Continued)

\begin{tabular}{|c|c|}
\hline Items & $\begin{array}{l}\text { Likert } \\
\text { Average }\end{array}$ \\
\hline Assessment criteria SSH & 3.8 \\
\hline $\begin{array}{l}\text { 32. The facilities, technology and simulation modalities, as well as standardized patients, and equipment are appropriate for the } \\
\text { summative assessment of individual and team knowledge and / or skills. }\end{array}$ & 4.1 \\
\hline 33. There are qualified consultants and staff to carry out the evaluation activities. & 3.9 \\
\hline 34. There is a systematic process for selecting the appropriate assessment tools. & 3.7 \\
\hline 35. There is adequate support for data analysis. & 3.5 \\
\hline Research criteria SSH & 3.3 \\
\hline 36. The mission statement includes a specific and credible commitment to investigative activities. & 3.4 \\
\hline 37. Instructors/educators/researchers demonstrate ability to conduct research. & 3.5 \\
\hline 38. There is a designated individual who is responsible for administering the research programs. & 3.0 \\
\hline $\begin{array}{l}\text { 39. The program emphasizes and supports the application of academic approaches to evaluate teaching, evaluation and / or systems } \\
\text { integration programs and to carry out validation studies of systems, approaches or simulation modules. }\end{array}$ & 3.1 \\
\hline 40. Research protocols are in accordance with accepted research standards. & 3.3 \\
\hline Systems integration criteria SSH & 3.5 \\
\hline $\begin{array}{l}\text { 41. The program works as an integrated institutional resource for Safety, Quality and Risk Management that uses the principles of } \\
\text { Systems Engineering, Human Factors, Quality, Safety, and/or Risk Management and engages in two-way feedback to achieve } \\
\text { business-level objectives and improve the quality of care. }\end{array}$ & 3.4 \\
\hline 42. The program has an established and committed role in the institutional processes of Quality and Safety Assessment. & 3.5 \\
\hline
\end{tabular}

We cannot find correlation between global GDP in education or GDP in health and number of simulation centers. One particularity of latinamerican countries are the differences about education funding. In some countries, the expenditure of education depends mostly on private funding, contrasting with the rest of Latin American countries [17].

The size and activities of the Latin American simulation centers were heterogeneous. This may be explained by the fact that some universities have several campuses in different regions of the same country, and the report shows the total activities as a single center, due to their administrative organization of the programs. Another explanation is that some centers conduct a significant number of OSCE evaluations to their own students and in processes of re-validation of international professional degrees, which influences the reporting of higher indicators or that some centers are dedicated to single professions and others attend multiple careers with large groups of students.

At the time of data collection, most of the simulation centers in Latin America were linked to university institutions. It is important to consider that centers linked to clinical institutions may have different forms of organization and focuses of action than those of university institutions, and that the number of centers or

Table 4 Total Score (Sum of total scores of quality self perception instrument) and Total Dimension Score (Sum of Scores by each dimension of quality self perception instrument)

\begin{tabular}{lllll}
\hline & $\begin{array}{l}\text { Ideal } \\
\text { score }\end{array}$ & $\begin{array}{l}\text { Mean of Mean } \\
\text { Scores }\end{array}$ & $\begin{array}{l}\text { Std. Deviation of mean } \\
\text { scores }\end{array}$ & $\begin{array}{l}\text { Percentage of mean scores obtained over ideal } \\
\text { score }\end{array}$ \\
\hline ASPIRE & 65 & 48,6 & 12,3 & $74,8 \%$ \\
SSH Core & 45 & 30,7 & 13,0 & $68,2 \%$ \\
SSH Teaching/Learning & 45 & 32,2 & 13,5 & $71,6 \%$ \\
SSH Evaluation & 20 & 13,5 & 5,8 & $67,7 \%$ \\
SSH Research & 25 & 14,5 & 7,0 & $58,1 \%$ \\
SSH Systems & 10 & 6,1 & 3,1 & $61,3 \%$ \\
Integration & & 145,7 & 38,3 & $69,4 \%$ \\
Total Scale & 210 & & &
\end{tabular}


simulation activities with a focus on clinical teams may be modified given the need for training of specific clinical competencies related to the current pandemic context.

It was reported that a simulation center using surgical simulation resources was created in 1961. Given the methodology defined in this study, based on self-reporting, no actions were taken to verify this statement. The literature describes the use of frozen biological material for surgical procedural training in 1986 [29], and in the early 1990s, the first recommendations for surgical training with simulation are found [30].

In our work, the professional profile of those who run the centers is heterogeneous in the profession, clinical specialty, academic degrees, and simulation training. The vast majority have received instruction with short courses, and only a few have fellow or international certifications. It is noteworthy that almost one sixth of them do not have specific training in the area.

Observing quality criteria is necessary for human activities that aim for excellence; this includes clinical simulation. In this study, the quality standards used were recognized as highly relevant by the directors of the simulation centers, mainly in teaching, learning environments, and ethical criteria. The research criteria were considered less relevant; this is consistent with the low region research visibility in the world ranking in the last decade [31].

Most of the simulation centers in the region were reported to be linked to universities. This may be related to the fact that the best rated dimensions globally correspond to those based on the ASPIRE criteria and the SSH teaching and learning criteria.

In 2013, Arthur et al. conducted a study with Delphi methodology in which the importance of maintaining standards in nursing simulation-based education is denoted [32]. Although the daily activity of the Latin America centers (participants, activities, etc.) was heterogeneous and relatively low, most of them showed a high number of activities related to the modalities of simulation resources used.

This study presents some limitations, such as the dependence of the self-report and the sincerity of the respondents [33], and the majority of responses come from three countries.

Another important consideration is that snowball sampling makes it challenging to determine the sampling error or make inferences about populations based on the obtained sample.

However, the internal consistency of the survey was high, and the responses were similar by country, size of the center, and profile of the director, which gives greater validity to the results [24]. Another research that attempts to characterize centers worldwide has a lesser response rate than our research [18].

In this case, the information that we get is important because it is the first attempt to characterize the complete region. We consider that this work is a basis to better understand how simulation centers operate in Latin America and open the opportunity for new research in this field.

Some of these research areas are the differences between simulation centers based in university and clinical institutions, or the relevance of the training of center directors in the development of educational programs. It is also important to inquire into the potential differences between self-reporting and independent observer evaluation.

\section{Conclusions}

Simulation-based education in health sciences has had an increasing development in Latin America. Growth alone is not a goal, and quality might be worth looking at.

Characterized centers are predominantly mediumsized, university-based, using standardized mannequins and patients to train clinical skills and procedures.

Agreement with the importance of quality and continuous improvement is high; it is low concerning research criteria and adherence to program evaluation mechanisms.

We recommend starting accreditation processes in Latin America and studies that measure the quality of simulation-based education in our region, based on objective observations more than in self-reporting.

\section{Abbreviations}

OSCE: Objective and Structured Clinical Examination; SSH: Society for Simulation in Healthcare; AMEE: Association for Medical Education in Europe; INACSL: International Nursing Association for Clinical Simulation and Learning ASPEAssociation of Standardized Patient Educators;

FLASIC: Federación Latinoamericana de Simulación Clínica - Latin American Federation of Clinical Simulation; CEPAL: Confederación

\section{Acknowledgements}

The research groups acknowledge to Federación Latinoamericana de Simulación Clínica (FLASIC) for their support. Also thanks to Jorge Bustos, José Luis García, Cinda Pérez, Fanny Solorzano, César Ruiz, Alejandro Sencion, and Nelson López.

\section{Authors' contributions}

$\mathrm{SA}, \mathrm{FM}, \mathrm{AD}, \mathrm{IB}$, and SN made substantial contributions to the conception and design of the work; all the authors made a substantial contribution to the data acquisition; FM and SA contributed significantly to the analysis and interpretation of the data; FM, SA, and AD drafted the work or substantively revised it. The authors made revisions, reads, and approved the final manuscript.

\section{Funding}

No fundings

\section{Availability of data and materials}

The datasets used and/or analyzed during the current study are available from the corresponding author on reasonable request. 


\section{Declarations}

\section{Ethics approval and consent to participate}

This article was approved by the Ethics Committee of Universidad del Desarrollo (CEl 46/2018) and the Ethics Committee of Universidade Federal de Santa Catarina (Parecer do Comitê de ética n 3.206.561). Informed consent was obtained from all participants.

\section{Consent for publication}

Not applicable

\section{Competing interests}

The authors declare that they have no competing interests.

\section{Author details}

'Núcleo de Simulación Interdisciplinar, Facultad de Medicina Clínica Alemana de Santiago Universidad del Desarrollo, Avenida Las Condes 12438 Lo Barnechea, Santiago, Chile. ${ }^{2}$ Universidad Autónoma de Chile, Pedro de Valdivia 425, Providencia, Santiago, Chile. ${ }^{3}$ Clinical Simulation Training Center, Hospital de Alta Complejidad en Red El Cruce Dr. Néstor Carlos Kirchner, Ministry of Health, Buenos Aires, Argentina. ${ }^{4}$ Department of Nursing, Federal Universidade Federal de Santa Catarina, Florianópolis, Brazil. ${ }^{5}$ Simulation Center, Faculty of Medicine, Universidad Diego Portales, Ejército, 141 Santiago, Chile. ${ }^{6}$ Simulation Center, Integrated School of Medicine, Nursing and Dentistry, Universidad Peruana Cayetano Heredia, Lima, Perú. ${ }^{7}$ Education and Simulation Research Group, VitalCare Centro de Simulación Clínica, Faculty of Medicine Universidad Alexander von Humboldt, Armenia, Colombia.

Received: 22 March 2021 Accepted: 3 October 2021

Published online: 12 November 2021

\section{References}

1. Economic Commission for Latin America and the Caribbean (ECLAC). Demographic observatory, 2014 [Internet]. Santiago, Chile: United Nations publication; [cited 2020 Apr 25]. Available from: https://repositorio.cepal.org/ bitstream/handle/11362/39228/1/S1500643_mu.pdf

2. OECD, Economic Commission for Latin America and the Caribbean, CAF Development Bank of Latin America and European Commission. Perspectivas económicas de América Latina 2019: Desarrollo en transición. 2019 Dec [cited 2020 Apr 25]; Available from: https://www.oecd-ilibrary.org/ development/perspectivas-economicas-de-america-latina-2019_g2g9ff1a-es

3. Society for Simulation in Healthcare, Council for Accreditation of Healthcare Simulation Programs. SSH Accreditation Process: Informational Guide for the Accreditation Process from the SSH Council for Accreditation of Healthcare Simulation Programs. [Internet]. Society for Simulation in Healthcare. 2017 [cited 2019 Sep 18]. Available from: Society for Simulation in Healthcare; 2017 [cited september 18, 2019]. Available in: https://www.ssih.org/Portals/ 48/Accreditation/SSH\%20Accreditation\%20Informational\%20Guide.pdf?ver= 2017-03-09-133118-517

4. ASPIRE International Recognition of Excellence in Education. Areas of excellence to be recognised [Internet]. Aspire-to-excellence.org. 2019 [cited 2019 Sep 18]. Available from: http://www.aspire-to-excellence.org/Areas+of+ Excellence/

5. Sittner BJ, Aebersold ML, Paige JB, Graham LLM, Schram AP, Decker SI, et al. INACSL Standards of best practice for simulation: past, present, and future. Nurs Educ Perspect [Internet]. September/October 2015;36(5):294-8. Available from: https://doi.org/10.5480/15-1670

6. Martínez G, Guarda E, Baeza R, Garayar B, Chamorro G, Casanegra P. Enseñanza de auscultación cardiaca a estudiantes y residentes de medicina mediante el uso de un simulador de ruidos cardiacos. Rev Esp Cardiol (Engl Ed) [Internet]. 2012;65(12):1135-6. Available from: https://doi.org/10.1016/j. recesp.2012.03.022

7. Armijo S. Consider this: how to integrate simulation into pre-licensure programs. In: Palaganas JC, Maxworthy JC, Epps CA, Mancini ME, editors Defining Excellence in Simulation Programs. Lippincott Williams \& Wilkins (LWW); 2014.

8. Boza C, León F, Buckel E, Riquelme A, Crovari F, Martínez J, Aggarwal R., Grantcharov T., Jarufe N., Varas J. Simulation-trained junior residents perform better than general surgeons on advanced laparoscopic cases. Surg Endosc
[Internet]. 2017;31(1):135-41. Available from: https://doi.org/10.1007/s00464016-4942-6

9. López-Herce J, Red de Estudio Iberoamericano de estudio de la parada cardiorrespiratoria en la infancia (RIBEPCl), Matamoros MM, Moya L, Almonte $\mathrm{E}$, Coronel $\mathrm{D}$, et al. Paediatric cardiopulmonary resuscitation training program in Latin-America: the RIBEPCI experience. BMC Med Educ [Internet]. 2017;17(1). Available from: https://doi.org/10.1186/s12 909-017-1005-1

10. Triviño BX, Vásquez MA, Mena MA, López TA, Aldunate RM, Varas PM, et al. Aplicación del Examen Clínico Objetivo Estructurado (OSCE) en la evaluación final del internado de pediatría en dos escuelas de medicina. Rev Med Chil [Internet]. 2000;128(9). Available from: https://doi.org/10.4067/ s0034-98872000000900013.

11. Bustamante ZM, Carvajal HC, Gottlieb BB, Contreras PJE, Uribe MM, Melkonian TE, et al. Hacia un nuevo instrumento de evaluación en la carrera de Medicina: Uso del método OSCE. Rev Med Chil. 2000;128(9):1039-44. https://doi.org/10.4067/S0034-98872000000900013.

12. Trejo-Mejía JA, Sánchez-Mendiola M, Méndez-Ramírez I, Martínez-González A. Reliability analysis of the objective structured clinical examination using generalizability theory. Med Educ Online[Internet]. 2016 Aug 18;21(1):31650. Available from: http://dx.doi.org/10.3402/meo.v21.31650, 21, 1

13. Matiz CH. La Práctica de la Simulación Clínica en las Ciencias de la Salud. Rev Col Cardiología. 2011;18(6):297-306.

14. Escudero Z. EX, Fuentes CM, Gonzalez V. MJO, Corvetto A. MA. Simulación en educación para ciencias de la Salud: ¿Qué calidad hemos alcanzado en Chile? ARS MEDICA Revista de Ciencias Médicas [Internet]. 2017 Jan 26 [cited 2019 Sep 19];26(2):16-20. Available from:http://www.arsmedica.cl/ index.php/MED/article/view/394

15. Motola I, Devine LA, Chung HS, Sullivan JE, Issenberg SB. Simulation in healthcare education: a best evidence practical guide. AMEE Guide No. 82 Med Teach 2013;35(10):e1511-e1530, DOl: 10.3109/0142159X.2013.818632.

16. Lewis KL, Bohnert CA, Gammon WL, Hölzer H, Lyman L, Smith C, et al. The association of standardized patient educators (ASPE) standards of best practice (SOBP). Adv Simul [Internet]. 2017;2(1). Available from: https://doi. org/10.1186/s41077-017-0043-4

17. CEPAL. Base de datos de inversión social en América Latina y el Caribe Available from: https://observatoriosocial.cepal.org/inversion/es/paises

18. Qayumi K, Pachev G, Zheng B, Ziv A, Koval V, Badiei S, et al. Status of simulation in health care education: an international survey. Adv Med Educ Pract. 2014:5:457-67. https://doi.org/10.2147/AMEP.S65451.

19. Zhao Z, Niu P, Ji X, Sweet RM. State of simulation in healthcare education: an initial survey in Beijing. JSLS. 2017;21(1): e2016.00090.Available from: https://doi.org/10.4293/JSLS.2016.00090

20. Russell E, Hall AK, Hagel C, Petrosoniak A, Dagnone JD, Howes D. Simulation in Canadian postgraduate emergency medicine training - a national survey. CJEM. 2018;20(1):132-41. https://doi.org/10.1017/cem.2017.24.

21. Binotti M, Genoni G, Rizzollo S, De Luca M, Carenzo L, Monzani A, et al. Simulation-based medical training for paediatric residents in Italy: a nationwide survey. BMC Med Educ [Internet].2019;19(1): 161.:Available from: https://doi.org/10.1186/s12909-019-1581-328

22. Stocker $M$, Laine $K$, Ulmer F. Use of simulation-based medical training in Swiss pediatric hospitals: a national survey. BMC Med Educ [Internet]. 2017; 17(1). Available from: https://doi.org/10.1186/s12909-017-0940-1

23. Feaster $S$, Lutz J, Reihsen $T$, Leland $F$, Shatzer J. Simulation center program metrics. In: Palaganas J, Maxworthy J, Epps C, Mancini M, editors. Defining Excellence in Simulation Programs. First Ed. United States: Wolters Kluwer; 2015. p. 25-38.

24. Machuca-Contreras F, Armijo-Rivera S, Díaz-Guio A, Nunes-de Oliveira S, Shibao-Miyasato H, Raúl N, Ballesteros-Mendoza I. Creación y propiedades psicométricas de un instrumento de autopercepción de calidad de programas y centros de simulación de Latinoamérica. Revista Latinoamericana de Simulación Clínica [Internet]. 2021; 3 (1):7-14. Available from: https://doi.org/10.35366/99863.

25. English T, Keeley JW. Internal consistency approach to test construction. In: The Encyclopedia of Clinical Psychology. Hoboken, NJ, USA: John Wiley \& Sons, Inc.; 2015. p. 1-3. https://doi.org/10.1002/9781118625392.wbecp156.

26. de Souza AC, Alexandre NMC, Guirardello, E.D.B. Psychometric properties in instruments evaluation of reliability and validity. Propriedades psicométricas na avaliação de instrumentos: avaliação da confiabilidade e da validade. Epidemiol Serv Saude [Internet]. 2017;26(3):649-59. Available from: https:// doi.org/10.5123/S1679-49742017000300022 
27. Mokkink LB, Prinsen CA, Bouter LM, de Vet HCW, Terwee CB. The COnsensus-based Standards for the selection of health Measurement INstruments (COSMIN) and how to select an outcome measurement instrument. Braz J Phys Ther. [Internet]. 2016;20(2):105-13. Available from: https://doi.org/10.1590/bjpt-rbf.2014.0143

28. Price LR. Test development. In Methodology in the Social Sciences. Psychometric Methods: Theory into Practice. New York, USA: The Guilford Press; 2017. p. 165-202.

29. Stotter AT, Becket AJ, Hansen JP, Capperauld I, Dudley HA. Simulation in surgical training using freeze dried material. Br J Surg. 1986 Jan;73(1):52-4. doi: 10.1002/bjs.1800730122. PMID: 3512022. CITA de simulacion con muestras biologicas data de 1980

30. Capperauld I, Hargraves J. Surgical simulation for general practitioners. Ann R Coll Surg Engl. 1991 Sep;73(5):273-275. PMID: 1929124; PMCID: PMC2499499.

31. Scimago Journal and Country Rank. World Report, Latin America, Health Professions 1996-2019; [Internet]. Scimagojr.com. [cited 2020 Jun 7]. Available from:https://www.scimagojr.com/worldreport.php?w=Latin\%20A merica\&area $=3600$

32. Arthur C, Levett-Jones T, Kable A. Quality indicators for the design and implementation of simulation experiences: a Delphi study. Nurse Educ Today [Internet]. 2013;33(11):1357-61. Available from: https://doi.org/10.101 6/j.nedt.2012.07.012

33. Burmeister LF. Principles of successful sample surveys. Anesthesiology. 2003; 99(6):1251-2. https://doi.org/10.1097/00000542-200312000-00003.

\section{Publisher's Note}

Springer Nature remains neutral with regard to jurisdictional claims in published maps and institutional affiliations.

Ready to submit your research? Choose BMC and benefit from:

- fast, convenient online submission

- thorough peer review by experienced researchers in your field

- rapid publication on acceptance

- support for research data, including large and complex data types

- gold Open Access which fosters wider collaboration and increased citations

- maximum visibility for your research: over $100 \mathrm{M}$ website views per year

At $\mathrm{BMC}$, research is always in progress.

Learn more biomedcentral.com/submissions 